\title{
Dietary supplementation with sodium humate improves egg quality and immune function of laying hens
}

\author{
A.R. Zhang ${ }^{1}$, S.A. Pirzado ${ }^{1}$, G.H. Liu ${ }^{1}$, Z.M. Chen ${ }^{1}$, W.H. Chang ${ }^{1}$, H.Y. Cai ${ }^{1}$, W.L. Bryden ${ }^{2}$ and A.J. Zheng ${ }^{1 *}$ \\ ${ }^{1}$ Key Laboratory of Feed Biotechnology of the Ministry of Agriculture and Rural Affairs \& National Engineering Research \\ Center of Biological Feed Development, Feed Research Institute, Chinese Academy of Agricultural Sciences, Beijing, \\ 100081, China P.R.; ${ }^{2}$ School of Agriculture and Food Sciences, University of Queensland, Gatton, QLD 4343, Australia; \\ zhengaijuan@caas.cn
}

Received: 7 June 2020/ Accepted: 20 July 2020

(c)2020 A.R. Zhang et al.

\section{RESEARCH ARTICLE}

POULTRY

\begin{abstract}
The aim of this study was to evaluate the influence of the dietary addition of sodium humate (HAS) on performance and immune response of laying hens during peak lay, over an eight-week period. Laying hens, aged 24 weeks old, were randomly allotted to four dietary treatments: a basal control diet or the basal diet supplemented with $0.1,0.3$ or $0.5 \%$ HAS. Each treatment had six replicates with 15 layers per replicate. Egg production, egg quality, serum antioxidant parameters and immunity indexes were measured. HAS had no significant effect on egg production or egg and shell quality, but all supplemental levels significantly improved Haugh unit values and egg yolk colour. Supplementation with all levels of HAS significantly increased serum immunoglobuline (Ig) level compared to the hens fed the control diet. Feeding either 0.1 or $0.5 \%$ HAS significantly increased serum IgM levels. The results indicated that dietary supplementation with HAS can enhance egg albumin quality and improve immunity in laying hens.
\end{abstract}

Keywords: sodium humate, egg-laying performance, immune function, laying hens

\section{Introduction}

Humates are formed by bacterial decomposition of decayed plant material and are considered to be growth promoting agents in poultry (Kocabagli et al., 2002). The active composition of humates includes humus, humic acid, fulvic acid, ulmic acid and some microelements (Stevenson, 1994). Humic acids contain cation and anion exchange sites. Humates are the salts of humic acid in which the exchange sites are $\mathrm{Ca}^{2+}, \mathrm{Na}^{+}, \mathrm{Al}^{3+}, \mathrm{K}^{+}$and $\mathrm{Fe}^{2+}$ rather than hydrogen. The antitoxic, anti-inflammatory and immunostimulatory properties of humic substances have been studied and it has been shown to enhance immunity and health status in human and veterinary research (Joone and Van Rensburg, 2004; Joone et al., 2003; Stackhouse and Benson, 1989). Importantly, sodium humate reduced cadmium availability and deposition in the liver, kidneys, and muscles of broilers (Herzig et al., 1994). The biological availability of sodium humate depends on route of administration, animal species, dose, and inclusion level in feed (Hampl et al., 1994).

Humic acids can improve gut health, nutrient absorption, and immune response in animals, including poultry, and supplying feed and water supplemented with humates promoted growth in poultry (Bailey et al., 1996). The addition of natrium humate to broiler diets has been shown to improve protein, mineral and lipid metabolism in chickens (Stepchenko et al., 1991). In broilers, improvements in growth performance, tibia ash content and morphology of the jejunal mucosa following dietary supplementation with humates have been reported (Kocabagli et al., 2002; Ozturk and Coskun, 2006; Taklimi et al., 2012).

The current feeding trial utilised Jinghong laying hens, which are a new breed from China, which has strong adaptability and is suitable for the local extensive breeding 
environment. Survival rate of this breed is much higher, up to $93 \%$, and the egg production peak is much longer, and can reach more than 180 days. Dietary supplementation with humates has been shown to improve egg shell quality from laying hens and partridges without affecting egg production and feed efficiency (Dobrzański et al., 2009; Ozturk et al., 2009).

Although the combined benefits of cations and the antitoxic, anti-inflammatory and immunostimulatory properties of humic acid is known, there is less research regarding the effects of humate supplementation on Jinghong laying hens. The present study evaluated egg-laying performance and immune response in Jinghong laying hens supplemented with sodium humate during peak egg production.

\section{Materials and methods}

The laying hen experiment was conducted in accordance with the Chinese guidelines for animal welfare and approved by the Animal Care and Use Committee of the Feed Research Institute of Chinese Academy of Agricultural Sciences.

\section{Birds, housing, diets, and experimental design}

Jinghong layer pullets were housed in layer cages at 16 weeks of age, in an environmentally controlled house. The cages were configured in a three-tier-rack system and the dimensions of each cage were; $100 \mathrm{~cm}$ wide, $70 \mathrm{~cm}$ deep and $45 \mathrm{~cm}$ high. At 24 weeks of age, after commencement of lay, 360 hens were individually assigned randomly to one of four treatment groups with six block replicates per treatment. Each replicate consisted of five consecutive cages housing three layers per cage. Hens had ad libitum access to feed and water throughout the trial. Layers were maintained under conventional temperatures $\left(15-20^{\circ} \mathrm{C}\right)$, relative humidity (60-70\%), with a 16-hour light and eighthour dark cycle per day. Light intensity was between 15-20 lux and the minimum ventilation rate was $2-3 \mathrm{~m} / \mathrm{s}$.

The four dietary treatments comprised a basal control diet $(\mathrm{CON})$ and three additional diets in which the basal diet was supplemented with either $0.1,0.3$ or $0.5 \%$ sodium humate (HAS). Dietary composition and nutritive value of the basal diet is presented in Table 1.

\section{Bird performance measurements}

The number of eggs laid, egg weight and mortality were recorded daily. Feed intake was recorded at four weekly intervals. The same period was used for the calculation of feed conversion ratio (feed to egg), egg laying rate, average egg weight, average daily feed intake and cracked egg rate. At 32 weeks of age, five eggs per replicate were randomly selected for the evaluation of egg parameters and eggshell quality.

\section{Blood sampling and analysis}

At the end of the study (32 weeks of age), two birds per replicate were randomly selected and blood samples were collected. The serum was kept at $-20{ }^{\circ} \mathrm{C}$ to determine serum antioxidant and immunity parameters. The levels of Newcastle disease antibody titre, immunoglobuline (Ig) A, IgM and IgG concentration in serum were measured using commercially available chicken enzyme-linked immunosorbent assay (ELISA) kits according to the manufacturer's instructions. Total antioxidant capacity (T-AOC) in serum was measured with a T-AOC assay kit and malondialdehyde (MDA) content in serum was measured using an MDA assay kit. All kits were purchased from the Jiancheng Bioengineering Institute (Nanjing, China).

Table 1. Ingredients composition and nutritive value of the basal diet for laying hens (as fed basis).

\begin{tabular}{|c|c|c|c|}
\hline Ingredients & Composition (g/kg) & Nutrient & Nutrient level \\
\hline $\begin{array}{l}\text { Corn }(7.8 \% \mathrm{CP}) \\
\text { Soybean meal }(43.5 \% \mathrm{CP}) \\
\text { Dicalcium phosphate } \\
\text { Limestone } \\
\text { DL-Methionine }(98 \%) \\
\text { Salt } \\
\text { Choline chloride }(50 \%) \\
\text { Zeolite powder } \\
\text { Vitamin and mineral premix }{ }^{1} \\
\text { Total }\end{array}$ & $\begin{array}{r}662.5 \\
228.4 \\
12.5 \\
85.1 \\
1.0 \\
3.0 \\
1.0 \\
5.2 \\
1.3\end{array}$ & $\begin{array}{l}\text { ME MJ/kg } \\
\text { CP } \% 2 \\
\text { Ca } \% \\
\text { Available P } \% \\
\text { Lys } \% \\
\text { Met } \% \\
\text { Met+Cys } \% \\
\text { Water } \% 2 \\
\text { Crude fat ether extract } \% 2 \\
\text { Crude fibre } \%^{2} \\
\text { Crude ash } \%^{2}\end{array}$ & $\begin{array}{r}11.08 \\
16.26 \\
3.58 \\
0.32 \\
0.84 \\
0.35 \\
0.68 \\
10.85 \\
2.47 \\
16.47 \\
11.54\end{array}$ \\
\hline
\end{tabular}

${ }^{1}$ Vitamin and mineral premix (per kg diet provide): $\mathrm{Cu} 8 \mathrm{mg}\left(\mathrm{CuSO}_{4} \cdot 5 \mathrm{H}_{2} \mathrm{O}\right) ; \mathrm{Fe} 60 \mathrm{mg}\left(\mathrm{FeSO}_{4}\right) ; \mathrm{Mn} 60 \mathrm{mg}\left(\mathrm{MnSO}_{4} \cdot \mathrm{H}_{2} \mathrm{O}\right) ; \mathrm{Zn} 60 \mathrm{mg}\left(\mathrm{ZnSO}_{4} \cdot \mathrm{H}_{2} \mathrm{O}\right) ; \mathrm{Se} 0.15 \mathrm{mg}$ $\left(\mathrm{Na}_{2} \mathrm{SeO}_{3}\right)$; I $0.3 \mathrm{mg}(\mathrm{KI})$; Vitamin A 10, $000 \mathrm{IU}$ (retinylacetate); Vitamin $\mathrm{D}_{3} 3,000 \mathrm{IU}$; Vitamin $\mathrm{K}_{3} 1 \mathrm{mg}$; Vitamin $\mathrm{B}_{1} 1 \mathrm{mg} ;$ Vitamin $\mathrm{B}_{2} 6 \mathrm{mg} ;$ Vitamin $\mathrm{B}_{12} 0.01 \mathrm{mg}$; Vitamin E $30 \mathrm{mg}$ (a-tocopherol acetate); $\mathrm{VB}_{3} 10 \mathrm{mg} ; \mathrm{VB}_{5} 40 \mathrm{mg} ; \mathrm{VB}_{6} 3 \mathrm{mg} ; \mathrm{VB}_{11} 0.3 \mathrm{mg} ; \mathrm{VB}_{12} 0.01 \mathrm{mg} ;$ Biotin $0.1 \mathrm{mg}$.

${ }^{2}$ Analysed values. 


\section{Statistical analysis}

Statistical analyses were performed using SPSS software (SPSS Inc., Chicago, IL, USA). Data were subjected to an analysis of variance using one-way ANOVA. Comparisons amongst the control and treatment groups was made using the Bonferoni multiple comparison test. For egg quality parameters, Pearson correlations were carried out to determine suitable significance for further regression analysis $(P<0.05)$. The regression analysis used both linear and quadratic models. The level of statistical significance was set at $P<0.05$. All values are presented as the means and pooled standard error of the mean (SEM).

\section{Results}

The hens were clinically normal throughout the study and no morbidity was observed or mortality was recorded.

\section{Laying performance}

The effects of dietary supplementation with sodium humate on laying hen performance and egg characteristics are shown in Table 2 and 3. Dietary sodium humate, at any inclusion level, had no significant effect on laying rate, egg weight, daily feed intake, feed conversion efficiency, or cracked egg rate $(P>0.05)$.

\section{Egg quality}

Dietary sodium humate had no significant effect on egg shape, albumen height or yolk weight $(P>0.05$; Table $4)$. However, Haugh unit values and yolk colour were significantly increased when hens were supplemented with sodium humate at all three levels of dietary inclusion $(P<0.05)$. No correlation was found between haugh unit, yolk colour and the inclusion of sodium humate respectively $(P>0.05)$.

\section{Eggshell quality}

The effects of supplemental dietary sodium humate on eggshell parameters are shown in Table 5. No significant effects due to humate addition at any level were detected for eggshell thickness, strength and relative weight $(P>0.05)$.

\section{Serum antioxidant parameters}

As shown in Table 6, no significant difference was found in serum T-AOC and MDA values from laying hens fed diets supplemented with sodium humate.

\section{Immunity parameters}

The impact of dietary supplementation with sodium humate on serum immunity parameters are shown in Table 7. No significant different relationship was found between

Table 2. Influence of dietary supplementation with sodium humate on laying rate, egg weight, daily feed intake, feed conversion ratio and cracked egg rate of laying hens (25-28 weeks post hatch). ${ }^{1,2}$

$\begin{array}{llllll}\text { Treatment } & \text { Laying rate }(\%) & \text { Egg weight }(\mathrm{g}) & \text { Daily feed intake }(\mathrm{g}) & \text { Feed conversion ratio } & \text { Cracked egg rate }(\%) \\ \text { CON } & 95.91 & 60.97 & 125.61 & 2.14 & 1.50 \\ 0.1 \% \text { HAS } & 95.67 & 60.49 & 124.33 & 2.15 & 1.36 \\ 0.3 \% \text { HAS } & 95.28 & 60.95 & 123.22 & 2.12 & 2.13 \\ \text { O.5\% HAS } & 96.15 & 60.91 & 125.76 & 2.15 & 0.02 \\ \text { Pooled SEM } & 0.56 & 0.13 & 0.97 & 0.935 & 0.14 \\ \text { P-value } & 0.961 & 0.548 & 0.794 & 0.296\end{array}$

${ }^{1} \mathrm{CON}=$ basal control diet; HAS = sodium humate diet.

${ }^{2}$ Each value represents the mean of six replicates (15 birds per replicate). Means in columns not sharing a common superscript are significantly different $(P<0.05)$.

Table 3. Influence of dietary supplementation with sodium humate on laying rate, egg weight, daily feed intake, feed conversion ratio and cracked egg rate of laying hens (29-32 weeks post hatch). ${ }^{1,2}$

$\begin{array}{llllll}\text { Treatment } & \text { Laying rate (\%) } & \text { Egg weight }(\mathrm{g}) & \text { Daily feed intake }(\mathrm{g}) & \text { Feed conversion ratio } & \text { Cracked egg rate }(\%) \\ \text { CON } & 91.35 & 61.61 & 124.85 & 2.22 & 1.26 \\ 0.1 \% \text { HAS } & 88.65 & 61.53 & 124.33 & 2.29 & 0.98 \\ 0.3 \% \text { HAS } & 86.86 & 61.53 & 125.38 & 2.35 & 1.29 \\ \text { O.5\% HAS } & 89.11 & 62.18 & 128.47 & 2.32 & 0.03 \\ \text { Pooled SEM } & 0.84 & 0.21 & 1.00 & 0.441 & 0.14 \\ \text { P-value } & 0.317 & 0.690 & 0.491 & 0.612\end{array}$

${ }^{1} \mathrm{CON}=$ basal control diet; $\mathrm{HAS}=$ sodium humate diet.

${ }^{2}$ Each value represents the mean of six replicates (15 birds per replicate). Means in columns not sharing a common superscript are significantly different $(P<0.05)$.

${ }^{3}$ Pooled standard error of mean. 
Table 4. Influence of dietary supplementation with sodium humate on egg yolk weight, albumen height, egg shape index, Haugh unit and yolk colour of laying hens (25-32 weeks post hatch). ${ }^{1,2}$

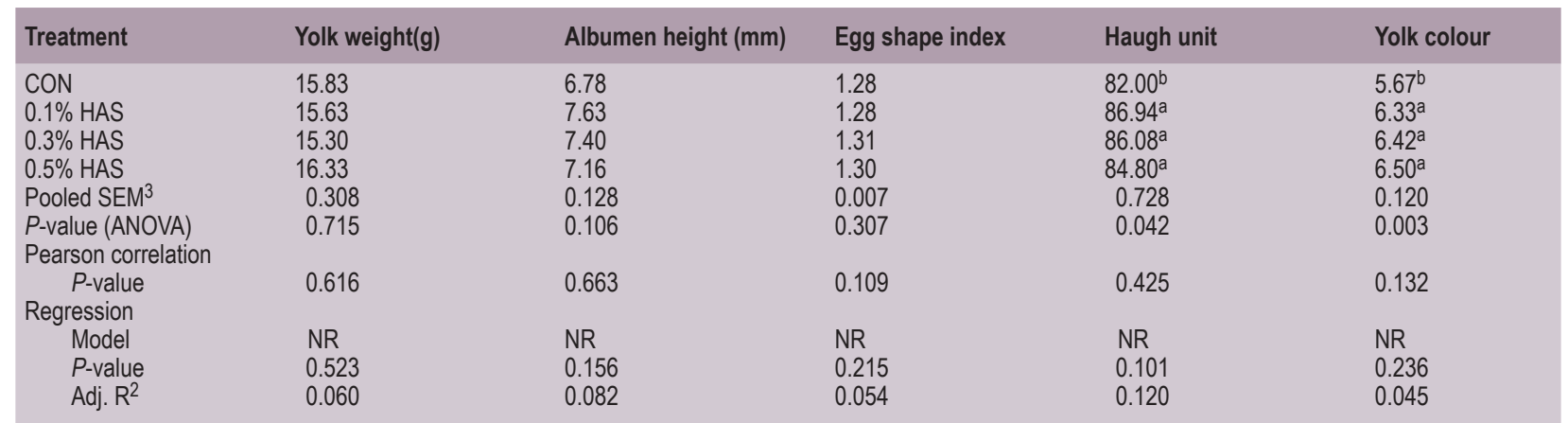

${ }^{1}$ Adj. $R^{2}$ = adjusted $R$ square; $C O N=$ basal control diet; HAS = sodium humate diet; $N R=$ no relationship.

${ }^{2}$ Each value represents the mean of six replicates (15 eggs per replicate). Means in column not sharing a common superscript are significantly different $(P<0.05)$.

${ }^{3}$ Pooled standard error of mean.

Table 5. Influence of dietary supplementation with sodium humate on eggshell thickness, eggshell strength and relative eggshell weight of laying hens (25-32 weeks post hatch). ${ }^{1,2}$

$\begin{array}{llll}\text { Treatment } & \text { Egg shell thickness }(\mathrm{mm}) & \text { Eggshell strength }(\mathbf{N}) & \text { Relative eggshell weight }(\%) \\ \text { CON } & 0.426 & 39.40 & 9.23 \\ 0.1 \% \text { HAS } & 0.424 & 38.63 & 9.62 \\ 0.3 \% \text { HAS } & 0.423 & 42.64 & 9.80 \\ 0.5 \% \text { HAS } & 0.424 & 42.96 & 9.48 \\ \text { Pooled SEM } & 0.002 & 0.941 & 0.177 \\ \text { P-value } & 0.989 & 0.255 & 0.735\end{array}$

${ }^{1} \mathrm{CON}=$ basal control diet; HAS = sodium humate diet.

${ }^{2}$ Each value represents the mean of six replicates ( 15 eggs per replicate). Means in columns not sharing a common superscript are significantly different $(P<0.05)$.

${ }^{3}$ Pooled standard error of mean.

Table 6. Influence of dietary supplementation with sodium humate on serum T-AOC and MDA levels of laying hens ( 32 weeks old post hatch). ${ }^{1,2}$

$\begin{array}{lll}\text { Treatment } & \text { T-AOC }(\mathrm{U} / \mathrm{ml}) & \text { MDA }(\mathrm{mM}) \\ \text { CON } & 6.11 & 4.00 \\ 0.1 \% \text { HAS } & 6.39 & 4.20 \\ 0.3 \% \text { HAS } & 5.90 & 3.93 \\ 0.5 \% \text { HAS } & 6.09 & 4.57 \\ \text { Pooled SEM } & 0.325 & 0.147 \\ P \text {-value } & 0.967 & 0.446 \\ { }^{1} \text { CON = basal control diet; HAS = sodium humate diet; MDA = malondialdehyde; T-AOC = total antioxidant capacity. } \\ { }^{2} \text { Each value represents the mean of six replicates (1 bird per replicate). Means in column not sharing a common superscript are significantly different }(P<0.05) . \\ { }^{3} \text { Pooled standard error of mean. }\end{array}$

treatments for Newcastle disease antibody titres $(P>0.05)$, but a linear response was found for IgA, which increased in line with the level of HAS in the diet $(y=0.049 x+0.904$; adj. $\left.\mathrm{R}^{2}=0.158 ; P=0.055\right)$. Supplementation with $0.1,0.3$ and $0.5 \%$ HAS significantly increased serum IgG levels compared to the hens in the control group $(P<0.05)$. This was best explained by the quadratic model $\left(y=-0.168 x^{2}+1.001 x+\right.$ 6.551; adj. $R^{2}=0.296 ; P=0.010$ ), and the best inclusion level of HAS was estimated to be $0.30 \%$ for IgG. Supplementation with 0.1 and $0.5 \%$ HAS significantly increased serum IgM levels $(P<0.05)$, and a quadratic trend was found for IgM $(P=0.078)$.

\section{Discussion}

There has been recent interest in the application of humic acid to poultry diets, with emphasis on meat chickens. This study evaluated sodium humate in laying hen diets, and found that supplemented birds remained in good health and humate had a positive impact on egg quality and bird immunity. 
Table 7. Influence of dietary supplementation with sodium humate on serum immunoglobuline $(\lg ) \mathrm{G}$, IgA, IgM levels and Newcastle disease antibody titre of laying hens (32 weeks old post hatch). ${ }^{1,2}$

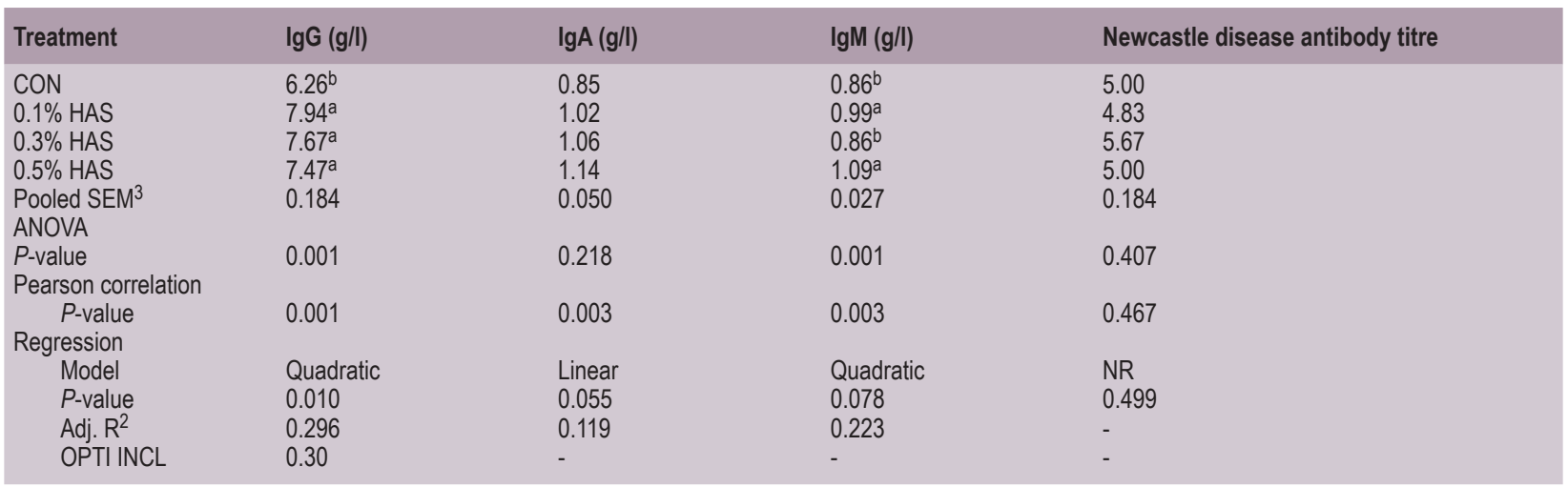

${ }^{1}$ Adj. $R^{2}$ = adjusted R square; CON = basal control diet; HAS = sodium humate diet; NR = no relationship; OPTI INCL = optimal inclusion level of sodium humate. ${ }^{2}$ Each value represents the mean of six replicates ( 1 bird per replicate). Means in column not sharing a common superscript are significantly different $(P<0.05)$.

${ }^{3}$ Pooled standard error of mean.

As has been shown in other studies with laying hens (Dobrzanski et al., 2007; Ozturk et al., 2009; Yörük et al., 2004), Japanese quail hens (Sakine et al., 2005) and partridge hens (Dobrzański et al., 2009), HAS supplementation did not affect laying rate, egg weight or feed conversion ratio. In contrast, some studies have shown an increase in egg production and feed efficiency following supplementation of layer diets with HAS, most likely because humic acids have been shown to enhance peptic activities and increase $\mathrm{N}$ digestibility through changes in gut $\mathrm{pH}$.

In the present study, HAS significantly improved albumen quality and increased yolk colour, which was similar to findings reported for laying quail (Sakine et al., 2005). HAS is dark brown and supplementation makes the feed darker. The reason that HAS increased the colour of egg yolk may have been due to the extra pigment being deposited into the egg yolk.

Albumen quality is measured in Haugh units and is considered to be a major indicator of freshness (Silversides and Scott, 2001). In the study, HAS enhanced Haugh units, which implied that supplementation improved the freshness of eggs. In contrast to these results, Hayirli et al. (2005) reported a linear decrease in Haugh units as humate supplementation level increased in Lohman layers. However, Yörük et al (2004) reported no effects of dietary supplementation with 0.1 and $0.2 \%$ humate on Haugh unit, yolk colour, albumen index, yolk index or egg shape index. No effect of dietary humic acid inclusion on egg yolk weight was seen in Isa Brown hens at the end of laying at 51-61 weeks of age (Ozturk et al., 2009).

No significant effects of dietary HAS were detected for eggshell thickness, strength or weight. These results agreed with previous studies where no changes in eggshell parameters were observed in response to the supplementation of humates in laying hens diets (Hayirli et al., 2005; Sakine et al., 2005; Yörük et al., 2004). However, other studies showed that egg shell quality was improved in Isa Brown layers fed diets supplemented with humic acid (Ozturk et al., 2009). Several reports have indicated no favourable effects of humates in broilers raised in conditions without pathogens (Aristimunha et al., 2019; Leeson et al., 2005), but there is improvement with supplementation of humic acid during immune stress (Edmonds et al., 2014). However, many gut enhancing effects of feed ingredients, including antibiotics, are not seen under sterile rearing conditions (Cowieson and Kluenter, 2019). The present results for egg quality may be attributed to the environmental conditions that the laying hens were kept under, where there were little challenges to growth and performance.

It has been established that trace elements contained in humate can have an antioxidant function (Lim and Paik, 2003). MDA is the main product of lipid peroxidation caused by oxygen free radicals and is an indicator for evaluating lipid peroxidation and antioxidant status (Sumida et al., 1989). In the current experiment, no variation was observed in serum T-AOC and MDA levels of laying hens fed HAS in comparison to the control group. These results demonstrated that the inclusion of HAS in diets did not change metabolites of lipid peroxidation, which are known to cause liver and cellular damage. It can be interpreted that antioxidant capacity was influenced by laying period or phase, and the present study showed that humic acid did not affect the antioxidant system of 25-32-week-old laying hens.

In birds, humoral immunity can be assessed by determining serum antibody titres in primary and secondary responses 
to Newcastle disease virus vaccine. In the current study, no significant differences were found in Newcastle disease antibody titres of laying hens fed diets containing HAS. However, an increase in antibody titre against avian influenza virus have been observed in broilers fed diets containing humate (Tohid et al., 2010).

Immunoglobulins are an important component of humoral immunity, and facilitate the deposition of soluble antigens, thereby improving the immune system's ability to eliminate antigens through phagocytosis (Dibner et al., 1998). In the current study, significant increases in serum IgG and IgM concentrations were observed in layers fed 0.1 and $0.5 \%$ HAS in the diet, which demonstrated that HAS was capable of elevating natural antibody production in laying hens. Humic acid has been shown to decrease heterophil count and the ratio of heterophils to lymphocytes, which has been positive correlated to immune stress (Rath et al., 2006). The available evidence indicated that such acids given to chickens via feed did not significantly affect mRNA expression of inflammatory cytokines itself, but improved immune response under lipopolysaccharide challenge in chicken macrophage cells (Zhou et al., 2014). The present study suggested that HAS may have immunostimulatory effect on laying hens.

\section{Conclusions}

In the published literature, the response of laying hens to dietary supplementation with HAS is variable and may reflect the source of humate used, strain of bird, stage of lay and type of diet fed. However, under the conditions of the current experiment, adding 0.1 to $0.5 \%$ HAS to the diet significantly improved egg quality and immune function of laying hens. Additional, studies are required to further delineate the biological effects of humate, thus permitting the strategic application of HAS to layer diets, especially in comparison to other feed additives that are purported to improve egg quality and bird health.

\section{Conflict of interest}

The authors declare that they have no competing interests.

\section{Acknowledgements}

This research was supported by the National Key R\&D Program of China no. 2018YFD0500600).

\section{References}

Aristimunha, P.C., Mallheiros, R.D., Ferket, P.R., Cardinal, K.M., Filho, A.L.B.M., Santos, E.T., Cavalcante, D.T. and Ribeiro, A.M.L., 2019. Effect of dietary organic acids and humic substance supplementation on performance, immune response and gut morphology of broiler chickens. The Journal of Applied Poultry Research 29: 85-94.
Bailey, C.A., White, K.E. and Domke, S.L., 1996. Evaluation of Menefee humate on the performance of broilers. Poultry Science 75: 84 .

Cowieson, A.J. and Kluenter, A.M. 2019. Contribution of exogenous enzymes to potentiate the removal of antibiotic growth promoters in poultry production. Animal Feed Science and Technology 250: 81-92.

Dibner, J.J., Knight, C.D., Kitchell, M.L., Atwell, C.A., Downs, A.C. and Ivey, F.J., 1998. Early feeding and development of the immune system in neonatal poultry. Journal of Applied Poultry Research 7: 425-436.

Dobrzanski, Z., Górecki, H., Chojnacka, K., Górecka, H. and Synowiec, M., 2007. Effect of dietary humic preparations on the content of trace elements in hens' eggs. American Journal of Agricultural and Biological Sciences 2: 234-240.

Dobrzański, Z., Trziszka, T., Herbut, E., Krawczyk, J. and Tronina, P., 2009. Effect of humic preparations on productivity and quality traits of eggs from Greenleg Partridge hens. Annals of Animal Science 9: 165-174.

Edmonds, M.S., Johal, S. and Moreland, S., 2014. Effect of supplemental humic and butyric acid on performance and mortality in broilers raised under various environmental conditions. The Journal of Applied Poultry Research 23: 260-267.

Hampl, J., Herzig, I. and Vlcek, J., 1994. Pharmacokinetics of sodium humate in chickens. Veterinary Medicine 39: 305-313.

Hayirli, A., Esenbuga, N., Macit, M., Lacin, E., Karaoglu, M., Karaca, H. and Yildiz, L., 2005. Nutrition practice to alleviate the adverse effects of stress on laying performance, metabolic profile, and egg quality in peak producing hens: I. The humate supplementation. Asian-Australasian Journal of Animal Sciences 18: 1310-1319.

Herzig, I., Hampl, J., Docekalova, H., Pisarikova, B. and Vlcek, J., 1994. The effect of sodium huminate on cadmium deposition in the organs of chickens]. Veterinary Medicine 39: 175-185.

Joone, G.K., Dekker, J. and Van Rensburg, C.E., 2003. Investigation of the immunostimulatory properties of oxihumate. Zeitschrift fur Naturforschung C 58: 263-267.

Joone, G.K. and Van Rensburg, C.E., 2004. An in vitro investigation of the anti-inflammatory properties of potassium humate. Inflammation 28: 169-174.

Kocabagli, N., Alp, M., Acar, N. and Kahraman, R., 2002. The effects of dietary humate supplementation on broiler growth and carcass yield. Poultry Science 81: 227-230.

Leeson, S., Namkung, H., Antongiovanni, M. and Lee, E.H., 2005. Effect of butyric acid on the performance and carcass yield of broiler chickens. Poultry Science 84: 1418-1422.

Lim, H.S. and Paik, I.K., 2003. Effects of supplementary mineral methionine chelates ( $\mathrm{Zn}, \mathrm{Cu}, \mathrm{Mn}$ ) on the performance and eggshell quality of laying hens. Asian-Australasian Journal of Animal Sciences 16: 1804-1808.

Ozturk, E. and Coskun, I., 2006. Effects of humic acids on broiler performance and digestive tract traits. In: Book of Abstracts of the $57^{\text {th }}$ Annual Meeting of the European Association for Animal Production. September 17-20, 2006. Antalya, Turkey, 301 pp.

Ozturk, E., Coskun, I., Ocak, N. and Erener, G., 2009. Effects of dietary humic substances on egg production and egg shell quality of hens after peak laying period. African Journal of Biotechnology 8: 11551159. 
Rath, N.C., Huff, W.E. and Huff, G.R., 2006. Effects of humic acid on broiler chickens. Poultry Science 85: 410-414.

Sakine, Y., Ergün, A., Handan, E., Suzan, Y. and Özsoy, B., 2005. Use of L-carnitine and humate in laying quail diets. Acta Veterinaria Hungarica 53: 361-370.

Silversides, F.G. and Scott, T.A., 2001. Effect of storage and layer age on quality of eggs from two lines of hens. Poultry Science 80: 1240-1245.

Stackhouse, R.A. and Benson, W.H., 1989. The effect of humic acid on the toxicity and bioavailability of trivalent chromium. Ecotoxicology and Environmental Safety 17: 105-111.

Stepchenko, L.M., Zhorina, L.V. and Kravtsova, L.V., 1991. The effect of sodium humate on metabolism and resistance in highly productive poultry. Nauchnye Doki Vyss Shkoly Biol Nauki 10: 90-95.

Stevenson, F.J., 1994. Humus chemistry - genesis, composition, reactions. John Wiley and Sons, New York, NY, USA.

Sumida, S., Tanaka, K., Kitao, H. and Nakadomo, F., 1989. Exerciseinduced lipid peroxidation and leakage of enzymes before and after vitamin E supplementation. International Journal of Biochemistry 21: 835-838.
Taklimi, S., Ghahri, H. and Isakan, M., 2012. Influence of different levels of humic acid and esterified glucomannan on growth performance and intestinal morphology of broiler chickens. Agricultural Sciences 3: 663-668.

Tohid, T., Hasan, G. and Alireza, T., 2010. Efficacy of mannanoligosaccharides and humate on immune response to Avian Influenza (H9) disease vaccination in broiler chickens. Veterinary Research Communications 34: 709-717.

Yörük, M.A., Gul, M., Hayirli, A. and Macit, M., 2004. The effects of supplementation of humate and probiotic on egg production and quality parameters during the late laying period in hens. Poultry Science 83: 84-88.

Zhou, Z.Y., Packialakshmi, B., Makkar, S.K., Dridi, S. and Rath, N.C., 2014. Effect of butyrate on immune response of a chicken macrophage cell line. Veterinary Immunology and Immunopathology 162: 24-32. 
